\title{
The effect of fungicides on growth of Fusarium fungi in vitro
}

\author{
Aleksandra Orina*, Olga Gavrilova, and Tatiana Gagkaeva \\ All-Russian Institute of Plant Protection, St. Petersburg, Pushkin 196608, Russia
}

\begin{abstract}
Four different fungicides that recommended to control seed-borne pathogens, were tested in this study. Three fungicides contain singly pyraclostrobin $(200 \mathrm{~g} / \mathrm{L})$, thiram $(400 \mathrm{~g} / \mathrm{L})$, fludioxonil $(25 \mathrm{~g} / \mathrm{L})$, and one fungicide contains together imazalil, metalaxyl, and tebuconazole $(50,40$, and $30 \mathrm{~g} / \mathrm{L}$, respectively). Comparative assessment of the fungicides at four concentrations of active substance $(10,100,1000$, and $10000 \mathrm{ppb})$ on the growth of ten strains of Fusarium spp. was studied in vitro tests. To visualize the effect of fungicides on fungal growth the strains were cultivated in $50 \mathrm{~mL}$ liquid Czapek medium containing fungicides in the range of concentrations. The fungicide based on pyraclostrobin was the most effective in growth inhibition of Fusarium fungi. Broadly, the using of this fungicide is confident way to control Fusarium species, which are serious threat to crop production. The sensitivity of $F$. acuminatum, $F$. graminearum, $F$. semitectum, $F$. culmorum, $F$. sporotrichioides, $F$. equiseti strains to fungicides was higher in compare with the strains belonging to $F$. oxysporum, $F$. solani, $F$. verticillioides, and $F$. proliferatum.
\end{abstract}

\section{Introduction}

Diseases caused by Fusarium fungi are a common occurrence on plants, often having a significant economic impact on yield and its quality. The different Fusarium species causes rot of root and stem base, seedling death, wilting, stunting, leave and head blight [1]. Thus managing diseases is an essential component of production for most crops.

There is no single method to provide effective control of Fusarium fungi on cultivated cereals, vegetables, and others crops. Typically management of pathogenic Fusarium species includes crop rotation, sanitation, and judicious use of fungicides. Unfortunately, there is not sufficient number of available varieties with measurable resistance to Fusarium diseases. A few Fusarium species which infect grains produce mycotoxins that can cause severe illness or even death in humans and animals when consumed $[2,3]$. In some cases, the infection with pathogenic fungi is increased greatly after seeds contact the ground.

\footnotetext{
*Corresponding author: orina-alex@yandex.ru
} 
Therefore, the protection of plants with effective fungicides against seed-borne pathogens during its seedling and early growth stages is essential for successful plant production.

In 2019 the using of 94 fungicides based on 20 active ingredients and their combinations is allowed for seed treatment to control the Fusarium pathogens in Russia [4].

The aim of this study was to determine in vitro the sensitivity of Fusarium fungi to fungicides widely used for seed treatment.

\section{Materials and Methods}

The ten single spore-strains of different Fusarium species were selected to study the effect of fungicides on their growth. The taxonomic status of strains was revealed according to the sum of their macro- and micromorphological characters [5]. The species and origin of strains included in the study are shown in table 1. The strains are maintained in the collection of the Laboratory of Mycology and Phytopathology (All-Russian Institute of Plant Protection, St. Petersburg, Russia).

Table 1. Origin of Fusarium spp. strains included in the present work

\begin{tabular}{|l|l|l|l|}
\hline $\begin{array}{l}\text { Collection } \\
\text { number of strains }\end{array}$ & Species & Substrate & Origin place and year \\
\hline MFP 1009021 & F. acuminatum Ellis \& Everh. & soybean & Primorsky Kray, 2017 \\
\hline MFG 102100 & F. culmorum (Wm.G. Sm.) Sacc. & barley & Kirov Oblast, 2017 \\
\hline MFP 1009031 & F. equiseti (Corda) Sacc. & soybean & Primorsky Kray, 2017 \\
\hline MFP 1009041 & F. graminearum & soybean & Primorsky Kray, 2017 \\
\hline MFP 1009051 & F. oxysporum Schltdl. & soybean & Primorsky Kray, 2017 \\
\hline MFP 1009061 & F. proliferatum (Matsush.) Nirenberg & soybean & Primorsky Kray, 2017 \\
\hline MFG 58998 & F. semitectum Berk. \& Ravenel & wheat & Krasnodar Kray, 2016 \\
\hline MFG 63301 & F. solani (Mart.) Sacc. & potato & Kazakhstan, 2006 \\
\hline MFG 64709 & F. sporotrichioides Sherb. & wheat & Primorsky Kray, 2007 \\
\hline MFG 59039 & F. verticillioides (Sacc.) Nirenberg) & maize & Krasnodar Kray, 2016 \\
\hline
\end{tabular}

Four commercially available fungicides, containing following active substances: \# 1 (50 g/L of imazalil, $40 \mathrm{~g} / \mathrm{L}$ of metalaxyl, $30 \mathrm{~g} / \mathrm{L}$ tebuconazole), \# 2 (200 g/L of pyraclostrobin), \# 3 (25 g/L of fludioxonil) and \# 4 (400 g/L of thiram) were chosen for the study. The effect of each fungicide was evaluated by the accumulation of biomass of Fusarium fungi during submerged cultivation in $50 \mathrm{~mL}$ of liquid Czapek medium (CZ) with fungicide in a $750-\mathrm{mL}$ Erlenmeyer flask in compare with the cultivation in the same medium without fungicide. The fungicides were diluted in sterile water to obtain a concentration of the active substance of $10 \mathrm{~g} / \mathrm{L}$, in the case of a three-component fungicide \# $1-10 \mathrm{~g} / \mathrm{L}$ of imazalil. Then ten-fold dilutions of the obtained solutions from $1 \mathrm{~g} / \mathrm{L}$ to 1 $\mathrm{mg} / \mathrm{L}$ were prepared. In each flask $50 \mu \mathrm{L}$ of the fungicide solution was added so that the final concentration of active substance reached to 10,100,1000, and $10000 \mathrm{ppb}$.

Each flask was inoculated with $50 \mu \mathrm{L}$ suspension $\left(2 \times 10^{4} \mathrm{CFU} / \mathrm{mL}\right)$ obtained from the fungal colony growing on potato-sucrose agar. In control, only inoculum was added to the medium without fungicides.

The flasks were incubated in INNOVA 44 (Eppendorf, Germany) for 6 days at $24{ }^{\circ} \mathrm{C}$ with constant shaking at $100 \mathrm{rpm}$. To determine fungal growth the culture supernatant was separated by vacuum filtration using pump Millipore XF5423050 (Alsace, France). The biomass was dried at $50{ }^{\circ} \mathrm{C}$ for a day and then weighed. The experiment was carried out in triplicate. Using probit analysis (Probit 2.0.0.6 program), the concentration of each fungicide leading to a $50 \%$ decrease in the fungal biomass (IC50) was calculated. 


\section{Results}

The dry weight of biomass after cultivation in liquid $\mathrm{CZ}$ in the control was $358 \pm 35 \mathrm{mg}$ for $F$. acuminatum, $F$. culmorum $-178 \pm 24 \mathrm{mg}, F$. equiseti $-277 \pm 21 \mathrm{mg}, F$. graminearum $283 \pm 7 \mathrm{mg}, F$. oxysporum $-365 \pm 18 \mathrm{mg}, F$. proliferatum $-336 \pm 27 \mathrm{mg}$, F. semitectum $256 \pm 6 \mathrm{mg}, F$. solani $-313 \pm 23 \mathrm{mg}, F$. sporotrichioides $-243 \pm 11 \mathrm{mg}$, and $F$. verticillioides $245 \pm 19 \mathrm{mg}$. The addition of the fungicides to the $\mathrm{CZ}$ led to significant effect, contributing to a decrease in the weight of fungal biomass (Fig. 1). It depends on the Fusarium species $(\mathrm{p}<0.0001)$, as well as on fungicide $(\mathrm{p}=0.02)$.

The concentration of the active substance, $\mathrm{ppb}$ :

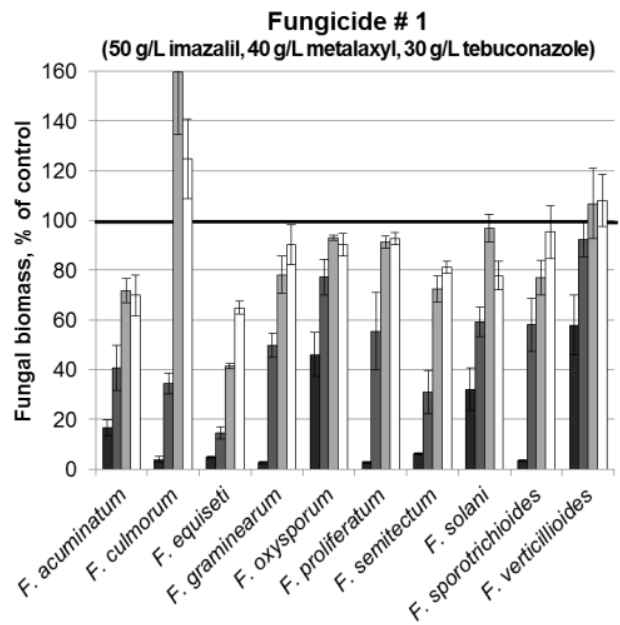

Fungicide \# 3

(25 $\mathrm{g} / \mathrm{L}$ of fludioxonil)

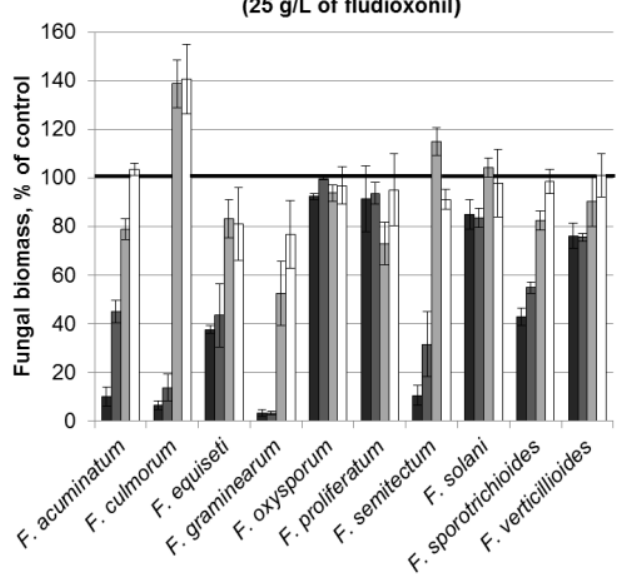

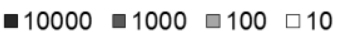

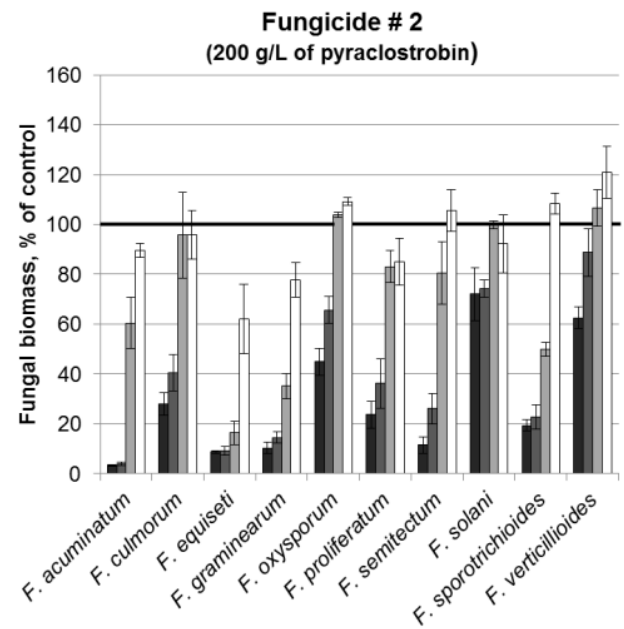

Fungicide \# 4

$(400 \mathrm{~g} / \mathrm{L}$ of thiram)

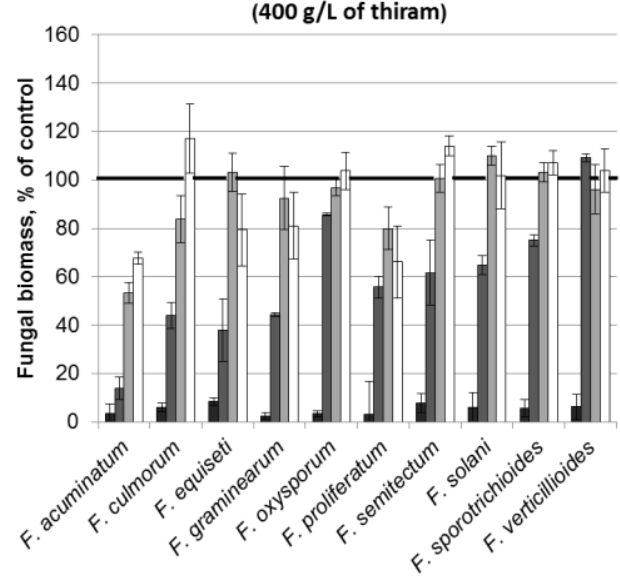

Fig. 1. The effect of fungicides in various concentrations on the accumulation of biomass of Fusarium spp. after cultivation in liquid Czapek medium $\left(24^{\circ} \mathrm{C}, 6\right.$ days $)$

The significant variation of sensitivity of Fusarium fungi to the different fungicides was observed. The high concentrations of the active substance of all fungicides (1 000 and $10000 \mathrm{ppb})$ reduced the growth of all fungal strains. The exception was fungicide \# 3 which did not affect the growth of $F$. oxysporum, $F$. proliferatum, $F$. solani and 
$F$. verticillioides strains. The low concentrations of the active substance of some fungicides stimulated the accumulation of fungal biomass. For example, the addition in $\mathrm{CZ}$ medium $100 \mathrm{ppb}$ of the fungicides \# 1 and \# 3 led to an increase of $F$. culmorum growth in compare with control ( $\mathrm{p}=0.04$ and $\mathrm{p}=0.02$, respectively).

\section{Discussion}

Studies in vitro have been conducted on the effect of some fungicides on growth of Fusarium fungi as a seed-treatment to improve seedling health. The results of probit analysis (Table 2$)$ showed that on average the fungicide \# $1(50 \mathrm{~g} / \mathrm{L}$ of imazalil, $40 \mathrm{~g} / \mathrm{L}$ of metalaxyl, $30 \mathrm{~g} / \mathrm{L}$ tebuconazole) the most effectively limited the growth of all ten strains belong to different Fusarium species.

Table 2. The concentration of fungicides that leads to half-maximum inhibition (IC50) of the biomass of Fusarium strains after submerged cultivation

\begin{tabular}{|l|c|c|c|c|}
\hline \multirow{2}{*}{ Fusarium fungi } & \multicolumn{5}{|c|}{ Concentration of active substance (IC50), ppb } \\
\cline { 2 - 5 } & $\mathbf{\# ~ 1}$ & $\mathbf{\# ~ 2}$ & $\mathbf{\# ~ 3}$ & $\mathbf{\# ~ 4}$ \\
\hline F. acuminatum & 532 & 117 & 660 & 61 \\
\hline F. culmorum & 815 & 1445 & 575 & 672 \\
\hline F. equiseti & 245 & 13 & 3523 & 544 \\
\hline F. graminearum & 485 & 58 & 66 & 774 \\
\hline F. oxysporum & 784 & 7810 & $>10000$ & 4905 \\
\hline F. proliferatum & 779 & 684 & $>10000$ & 1037 \\
\hline F. semitectum & 357 & 547 & 861 & 1491 \\
\hline F. solani & 2799 & $>10000$ & $>10000$ & 1528 \\
\hline F. sporotrichioides & 662 & 98 & 869 & 1992 \\
\hline F. verticillioides & 14541 & 19498 & $>10000$ & 6302 \\
\hline
\end{tabular}

A similar reaction of the strains $F$. oxysporum, $F$. proliferatum, $F$. solani, and $F$. verticillioides to the addition of fungicides was revealed. The fungicide \# 3 (25 g/L of fludioxonil) did not inhibit growth of these fungi. Generally these strains showed low sensitivity to the active substances (IC50 from 684 to $>10000 \mathrm{ppb}$ ) compared with other fungi included in the study.

Overall, $F$. acuminatum, $F$. equiseti, $F$. semitectum, and $F$. sporotrichioides strains showed an average level of sensitivity to the fungicides (IC50 varied between 13 and 3523 $\mathrm{ppb}$ ). The fungicide \# 2 (200 g/L of pyraclostrobin) was most effective for control of these strains.

The strains of closely related species $F$. culmorum and $F$. graminearum turned out to be the most sensitive to fungicides (IC50 varied between 58 and $1445 \mathrm{ppb}$ ), among which fungicide \# 3 (25 g/L of fludioxonil) was the most effective. These species are most aggressive to cereals and dangerous due to the production of mycotoxins. Perhaps the high sensitivity of these species to analyzed fungicides is the result of screening the substances for antifungal activity against these pathogens.

Knowledge of the sensitivity of different fungal species to particular active substances is extremely important when plan protection systems and choose the most effective fungicides. Accurate diagnosis of the etiology of crop diseases, as well as the correct identification of Fusarium pathogen and determination of its area, are necessary to predict the effect of used fungicides. The seed treatment with fungicides should be a mandatory technique for obtaining a high quality yield.

This study was supported by the Russian Science Foundation (project no. 19-76-30005). 


\section{References}

1. D.W. Parry, P. Jenkinson, L. McLeod, Plant. Pathol. 44, 207 (1995)

2. S.P. McCormick, A.M. Stanley, N.A. Stover, N.J. Alexander, Toxins, 3, 802 (2011)

3. N.A. Foroud, D. Baines, T.Yu. Gagkaeva, N. Thakor, A. Badea, B. Steiner, M. Bürstmayr, H. Bürstmayr, Toxins, 11, 634 (2019)

4. State catalog of pesticides and agrochemicals permitted for use on the territory of Russian Federation (Ministry of Agriculture of the Russian Federation, Moscow, 2019)

5. W. Gerlach, H.I. Nirenberg, The genus Fusarium-A Pictorial Atlas (Mitteilungen aus der Biologischen - und Forstwirtschaft, Berlin-Dahlem, 1982) 